\title{
Design and evaluation of 5G-based architecture supporting data-driven digital twins updating and matching in seismic monitoring
}

\author{
Vincenzo Gattulli ${ }^{1}$ (D) Fabio Franchi ${ }^{2} \cdot$ Fabio Graziosi $^{2} \cdot$ Andrea Marotta $^{2}$. \\ Claudia Rinaldi ${ }^{2}$. Francesco Potenza ${ }^{3}$. Umberto Di Sabatino ${ }^{4}$
}

Received: 23 July 2021 / Accepted: 16 January 2022 / Published online: 14 February 2022

(C) The Author(s) 2022

\begin{abstract}
Digital Twins (DT) models are gaining special attention in the management and maintenance of facilities. The quality of data contained in these models may be enhanced by the use of processed information coming from long-term Structural Health Monitoring (SHM). In this case real time processing and updating in systems using sensor networks for SHM need low latency and reliable communication. This paper presents a solution for exploiting DT models for SHM and early warning solutions improvement. The case study scenario resides within the $5 \mathrm{G}$ experimentation in the city of L'Aquila and it exploits a highly adaptable sensor board and a 5G Multi-Access Edge Computing architecture.
\end{abstract}

Keywords Structural health monitoring (SHM) · Earthquake early warning (EEW) · $5 \mathrm{G}$ network $\cdot$ Massive machine-type communications (mMTC) - Ultra-reliable and low latency communications (uRLCC ) · Multiaccess edge computing (MEC) · MEMS accelerometers

\section{Introduction}

The recent advances in connectivity technologies have brought to the creation of new terms to properly define the possible scenarios. Internet of Everything (IoE) has been recently adopted to indicate a paradigm comprising both previously defined Internet of Things (IoT) and Internet of Humans ( $\mathrm{IoH}$ ) concepts within a variegate scenario where data can be exchanged through Machine to Machine (M2M) or Machine to Humans (M2H). To these paradigms several application domains such as industry 4.0, e-health, smart grids, smart cities, safety and more refer.

This contribution mainly focuses on the application of IoT paradigm, in the urban scenario of the city of L'Aquila (ITALY), that is almost unique, since a reconstruction phase after the strong earthquake that hit the town in 2009 , is still an on-going process, Chiarabba et al. (2009). This represents a great opportunity to direct the overall urban design toward

Vincenzo Gattulli

vincenzo.gattulli@uniroma1.it

Extended author information available on the last page of the article 
a "smart city" view, focusing at first toward safety and ecology. In this context, a focus toward Structural Health Monitoring solutions has been seen as an occasion to monitor buildings structures not only for early warning solutions in earthquakes events, but also to control and mitigate service conditions of construction in relations to comfort, energy savings and optimized maintenance. For all these aspects an integrated approach to digital twins designed for multipurpose applications appears to be very attractive. Here, the focus is to evaluate the health of a structure by timely identifying what are the main causes (e.g deterioration of the material or heavy structural damage) which may affect the use of the structure. Such causes can be induced by different circumstances like manufacturing defects, poor maintenance or exposition to unexpected or extreme events (earthquakes or blasts).

Given the potential advantages, SHM systems have been largely implemented in structures falling in various fields (e.g. civil, aerospace, railway). It is worth noticing that given the 3 main different types of structures (i.e. buildings Dolce et al. (2017), bridges and infrastructures Anastasopoulos et al. (2021), Giordano et al. (2021), Rainieri et al. (2020), cultural heritages Kita et al. (2019), Potenza et al. (2015) and towers Venanzi et al. (2020), Gentile et al. (2016)) different attentions and instructions must be ensured in the phases of monitoring system design.

In the SHM scenario the first important element is a network of sensors that is permanently attached to the structure to be monitored. This network brings an important advantage because it does not require human intervention as Non-Destructive Testing (NDT) procedures commonly provided, Güemes et al. (2020). Sensors may be accelerometers, fiber optics sensors, piezoelectric wafers, microelectromechanical systems (MEMS) and many more.

A second element is given by the communication architecture that is exploited for data exchange between nodes of the network and the data processing unit. Since it has been shown that a major fraction of the overall cost of a traditional SHM system is primarily related to wiring costs, Lynch and Loh (2006), going wireless represents a significant innovation opportunity in SHM field. In this context, the opportunity coming from the choice of the city of L'Aquila as one of the five Italian cities to host a 5G trial, has pushed the exploitation of this communication technology in the SHM field, Antonelli et al. (2018).

Referring to the $5 \mathrm{G}$ vision and its three generic objectives to be supported, Shafi et al. (2017), i.e. enhanced Mobile Broad-Band (eMBB), massive Machine-Type Communications (mMTC) and ultra-Reliable and Low Latency Communications (uRLCC), the SHM system can be referred to the mMTC or uRLCC context, depending on the operational scenario. Indeed, the case of data collection and processing from sensors in monitored buildings, considering their large number, can be referred to the mMTC context. Vice versa, during a seismic event or just after it, the use case requires high reliable connectivity and low latency: these features refer to the uRLLC context. It is interesting to evaluate and to experiment the ability of the $5 \mathrm{G}$ network to dynamically adapt to the changing scenarios.

Another aspect to be taken into account while conceiving with SHM is the way through which data are processed and exploited to get advantages from the installed sensors network. Starting from the definition of simplified models, the information provided by SHM systems could be used to improve the knowledge of the structural behavior of a building/ infrastructure, Gattulli et al. (2021).

This work refers to monitoring and control systems that allow not only to give useful information to detect the damage induced by a catastrophic event, but also to maintain its strength and serviceability during the whole design life, Ceci et al. (2013). 
Various vibration control systems have been proposed in literature (i.e., active, passive, and semi active); some of them relying on simple approaches such as PID controllers, others exploiting a dynamical model, which can be difficult to obtain when the structure to be considered is complex, Di Girolamo et al. (2020), Smarra et al. (2020). It is worth noting that if from one hand it is important to have a detailed model structure for applying efficient and reliable evaluating solutions, especially in the case of a catastrophic event, on the other hand special care has to be given to the amount of data that these models eventually require to manage, which sometimes become prohibitive from a practical point of view. For this reason, special attention has to be given to the achievement of the proper trade-off between the simplicity of a model and its ability to faithfully represent the behaviour of a building under certain inputs.

Finally it is important to notice that the sampling intervals need to be tight as it is necessary to be able to quickly react to very rapid external disturbances (e.g., earthquakes). This implies that the dedicated hardware intended for computation must be able to manage the large amount of data coming from the sensors in the structures and compute the control actions in times of the order of milli/microseconds.

This paper presents a 5G-based communication architecture that is able to manage SHM and EEW solutions at the same time, guaranteeing the satisfaction of their different requirements. The opportunity of satisfying very different and sometimes strict applications constraints without the need of using different communication solutions is offered for the first time by the $5 \mathrm{G}$ paradigm that thus allows to design multi-functional and multipurpose scenarios. A case study scenario, based on DT models, is presented in order to validate the stated advantages of the proposed platform.

\section{Structural health monitoring and earthquake early warning}

Structural Health Monitoring is a vital tool to improve the safety and maintainability of critical structures such as bridges and buildings. SHM provides real-time and accurate information about the structural health condition. It is a process of non-destructive evaluations to detect location and extent of damage, calculate the remaining life, and predict upcoming accidents.

The implementation and usefulness of a permanent seismic monitoring systems network installed in public buildings (but also some bridges and a dam) along the Italian territory has been assessed and described in Dolce et al. (2017), where the proposed network, called OSS (acronym of the Italian name "Osservatorio Sismico delle Strutture") is able to carry on a real-time post-earthquake damage assessment.

In SHM systems one of the main tasks is to detect damage that can influence both global and local structural behavior. About the first task (global) Vibration-Based Monitoring (VBM) is certainly the most widely used. Indeed, a possible variation of the modal characteristics (frequency, shape and damping) could be related to the beginning of a damage since they are in relation with stiffness and mass of a structure, Limongelli and Giordano (2020), Kita et al. (2020).

It is worth highlighting that sometimes daily experimental tests could constitute an alternative to install a monitoring system. In this latter case, if from one side they are easier to be performed (especially when tests are carried out under ambient vibrations), on the other side they are able to supply less information than the ones provided by a permanent monitoring system. In this case the information will be useful to update 
forecasting finite element models for carrying out more accurate checks or evaluate the vulnerability of a structure, Diaferio et al. (2015a), Foti (2015), Diaferio et al. (2015b), Foti et al. (2020).

Instead, the second task (local) is easier performed by visual inspection techniques. In recent times, especially due to safety issues of the inspectors (sometimes is very hard to reach inaccessible areas), semi-automatic computer-aided procedures are under development putting together both image processing techniques and robotized systems, Potenza et al. (2020).

VBM systems are traditionally carried out processing accelerometric measurements induced by both ambient vibrations and seismic events using well-kwon techniques like Frequency, Brincker et al. (2001), or Enhanced, Jacobsen et al. (2008), Domain Decomposition (FDD or EFDD) and Stochastic Subspace Identification Reynders and De Roeck (2008). However, in a recent work, Anastasopoulos et al. (2021), some promising results have been achieved by strain data that are relatively low cost and allow to implement a dense measurement grid. It worth to highlight that the realization of a SHM requires time and considerable economic investments for which could be useful to perform rapid daily experimental dynamic tests for calibrating a forecast numerical model. In Gattulli et al. (2021) thanks to the huge volume of data coming from two-days of experimental campaign on a suspension bridge it has been possible to update both numerical and analytical mechanical model able to well represent the dynamic behavior. Moreover, in the cases of the towers, some predictive formulas have proposed to evaluate the modal characteristics based only on the knowledge of the geometrical features without carrying out dynamic tests, Diaferio et al. (2018). Long-term SHM data need also to be depurated from the effect of the environmental conditions as temperature and humidity, Gentile et al. (2019), Ubertini et al. (2018), Pitilakis et al. (2016). For this reason, data driven methods have found great applicability since they are able to explore the internal characteristics of the raw measured response and deeply detect the damage. Some interesting example are illustrated in Flah et al. (2021), Peng et al. (2021), Kaya and Safak (2015).

Different typologies of monitoring actions (dynamic analysis-oriented monitoring, seismic analysis-oriented monitoring, crack growth-oriented monitoring, environmental- or chemical-oriented monitoring) may have different or conflicting requirements. For example, dynamic analysis-oriented monitoring systems must guarantee a precise measurement synchronization, Krishnamurthy et al. (2008), while this requirement may result less compelling when monitored quantities are slowly variable (e.g. the case of crack growth monitoring). Data gathered are exploited in order to verify the buildings performance over time enabling a continuous evaluation of their safety and the opportunity of planning proper restoration activities to reduce their vulnerability. Sensor networks are able to transmit the measured data to a central data collector in order to process them in a proper way. The ultimate goal of this kind of systems is to build a wide monitoring network with low-cost technologies allowing the development of processes of qualitative analysis and representation of data collected by the sensors (e.g. georeferenced triaxial accelerometer data). The fundamental building blocks of sensor networks for SHM, which determine their performance in terms of reliability, energy consumption and economic issues, are: sensors, microcontrollers and communication interfaces. The latter aspect has seen a lot of research and implementation efforts for exploiting the advantages coming from wireless connections such as greater flexibility and low cost deployment, Lynch and Loh (2006). In general, a lot of sensor networks designs are available for SHM either in form of academic prototypes or 
commercial products, all of them constituted by the previously hinted building blocks, see for instance Lynch and Loh (2006), Mustapha et al. (2021), Ostachowicz et al. (2019) and references therein.

This analysis also aims at evaluating the possibility of using this type of low cost distributed systems for the characterization of environmental pressures on the architectural heritage. The building monitoring system is the basis for the implementation of different kind of systems used to protect the health of citizens in case of natural disasters (earthquakes or other catastrophic events). It exploits the ability to constantly track the status of the structures in a timely manner to detect the occurrence of dangerous events and activate, when necessary, proper mechanisms for emergency response. The monitoring systems are used to get an immediate assessment of the safety level of the building, at both global and individual level.

The idea behind Earthquake Early Warning (EEW) is to use the SHM system to detect a seismic event and to propagate a message reporting the event detection (EEW message) to all the buildings that may be damaged by the disaster event. While the seismic detection in the local building can trigger reactive safety actions to compensate the effect of the disaster without any guarantee of effectiveness, the EEW message reception triggers preventive safety actions in the nearby buildings that, if applied with adequate timing, can increase citizens and facilities safety as shown in Fig. 1.

Potential preventive safety actions that can be triggered by EEW include initiation of elevator recall to ground floor procedures, placement of sensitive equipment in safe mode, securing of hazardous materials, halt production lines to reduce damage, unlocking of exit doors, switch on of emergency lights. Earthquake events are normally characterized by the occurrence of body and surface waves. Body waves have lower energy and propagates with a speed between 1.5 and $8 \mathrm{~km} / \mathrm{s}$ while surface waves propagate with lower speed but, on the other hand, transfer a higher energy with respect to body ones and therefore are more dangerous, Di Stefano et al. (2011). The difference in propagation speed between body and surface waves implies a delay of arrival at different places in the surface that can be effectively utilized to implement preventive safety actions. That being said, once the EEW message is generated, every millisecond spent in the propagation of the message corresponds to an increase of almost $8 \mathrm{~m}$ of the radius of the area reached by the earthquake. On the other hand, the reduction of $1 \mathrm{~ms}$ of the EEW propagation time corresponds to an increase of $8 \mathrm{~m}$ of the area where to implement safety actions. These data stress the importance of exploiting a $5 \mathrm{G}$ connection for early warning purposes given the unprecedented low latency level guaranteed by this new generation of networks. At the same time $5 \mathrm{G}$ is able to guarantee a proper functioning of the system also under the SHM state. This level of flexibility is due to the network slicing concept that is presented in the following section.

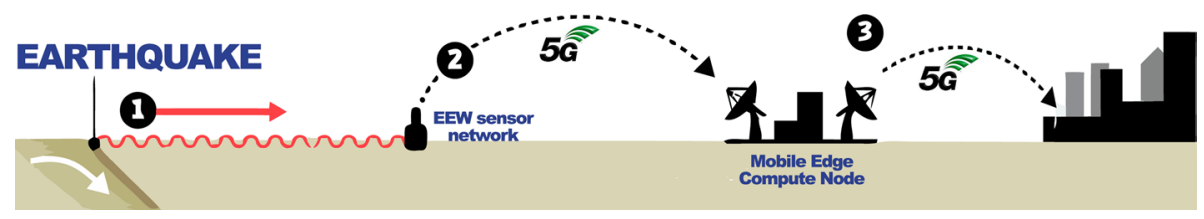

Fig. 1 5G EEW system functional scheme 


\section{5G architecture supporting structural health monitoring and earthquake early warning}

Compared to the previous mobile communications technologies $5 \mathrm{G}$ offers an unprecedented level of flexibility to support heterogeneous services. In order to achieve this goal it leverages several enabling technologies and novel network paradigms such as:

- Software Defined Networking (SDN) that allows to control via software the behaviour of network elements in order to adapt to different network conditions and to enforce service-specific traffic requirements

- Network Function Virtualization (NFV) allows to reproduce the behaviour of traditional hardware-based network functions (switches, routers, firewalls, etc.) via virtualization techniques over general purpose machines. This way, the network can be flexibly reconfigured and service components can be orchestrated over different physical locations, i.e. datacenters, to obtain the desired service performance.

- Network Slicing (NS) by combining the advantages deriving from SDN and NFV allows to offer to different services virtual slices with specific performance tailored to the different services over a common physical infrastructure. The slices are composed by involving the different network segments traversed by the traffic. This includes wireless network, optical transport network, and computation infrastructure.

- Multi-Access Edge Computing (MEC) by leveraging NFV, MEC allows to move to the edge computation elements devoted to a specific service. This approach has many advantages: (i) it allows to reduce the latency experienced by the users since reduces the travel of the packets; (ii) reduces the overall traffic into the network thus avoiding congestion for the operator at the price of introducing replicas of elaboration elements at the edge; (iii) it allows to achieve better Quality of Experience for multimedia services.

Parallel to the above described building blocks, 5G introduces novel techniques in the radio segment of the network devoted to offer not only higher throughput, but also higher reliability levels and lower latency depending on the requirements of the specific service.

With respect to the above described SHM and EEW system, one can observe that the two applications are characterized by significantly different requirements. Even if both services are based on the sensing of data performed by the same sensor nodes, the data transmitted for the two applications can be treated differently by the network elements. In fact, the traffic for the SHM can be treated with no particular performance guarantees since it is only devoted to monitoring purpose. On the other hand, the traffic of the EEW application represents a critical traffic with low latency and high reliability requirements since it is devoted to activate safety actions.

In order to fulfill such heterogeneous requirements the adopted 5G network architecture is configured to support two different network slices, for the SHM and EEW respectively, as shown in Fig. 2. The EEW slice is configured to schedule the traffic of the EEW with very high priority in the radio segment to achieve low latency; when the packets leave the $5 \mathrm{G}$ base station they have to traverse the so called optical transport network which is configured to offer protection against failures of physical layer (e.g. fiber cuts); finally the software for the elaboration of the EEW messages is deployed at the edge of the network (thanks to MEC capabilities) in order to obtain a very low latency and can be scaled and replicated to offer higher performance and survivability against disasters. On the other 


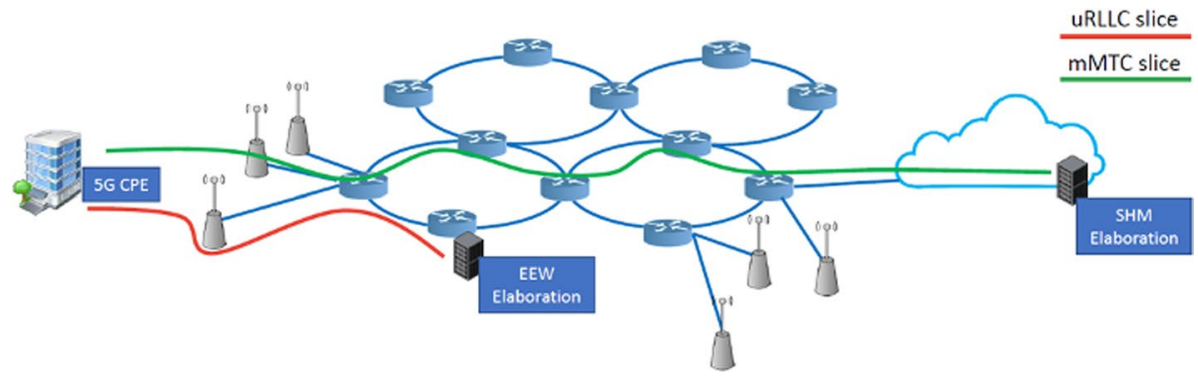

Fig. 2 uRLLC and mMTC slices: the red path is intended for EEW traffic while the green one represent the date addressed to a cloud SHM elaboration node

hand the SHM slice is configured to forward the traffic over the physical infrastructures on a best-effort manner and the function responsible for the elaboration of the messages is deployed over a remote cloud which is characterized by higher cost efficiency from the service provider's viewpoint.

\section{Service development}

This Section describes the deployed architecture supporting an experimentation of the designed system for a building belonging to the University of L'Aquila within the $5 \mathrm{G}$ trial.

\subsection{Sensor board design}

SHM-Board $v 2$ has been designed as a highly versatile and high-performance device for real-time SHM of infrastructures or buildings.

Figure 3 shows the device which takes advantage by the experience made in the filed with the IMOTE board used in the 5-years continuous structural monitoring of the Basilica of Collemaggio after the 2009 L'Aquila earthquake, Potenza et al. (2015).

The new SHM-Board $v 2$ is based on an ultra-low-power micro-controller which offers numerous communication and high-performance interfaces: through its 12-bit ADC, it is connected to a low-noise MEMS accelerometer (Kionix KXRB5-2050), mounted directly on the board, that is always active in order to detect accelerations above a configurable threshold.

External low-noise MEMS accelerometers can also be used. SHM-Board $v 2$ is equipped with 4-channels 24-bit ADC able of sampling at $100 \mathrm{~Hz}$ and on-board data processing in order to minimize the total amount of data to be transmitted. Two accelerometers, suited for structural health monitoring, were identified and tested.

The board has been designed in order to examine the possible adoption of low cost, un-calibrated, MEMS accelerometers for both SHM and EEW scenarios. However, a calibration procedure has been defined for the MEMS accelerometers in order to compare the estimation of the structural response provided by the data processing with and without calibration.

From the communications point of view, SHM-Board $v 2$ has an Ethernet interface (from which it can be powered via $\mathrm{PoE}$ ) and other interfaces to connect more peripherals. The board also provides the capability to communicate wirelessly with other nodes of the 
Fig. 3 The sensor board developed for the experimentation

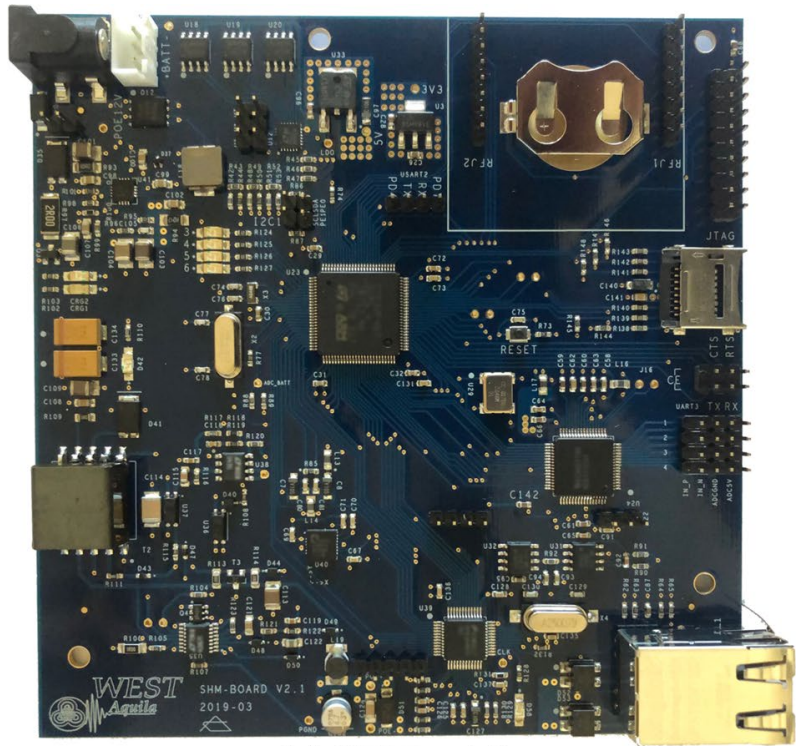

(a) SHM Board V2

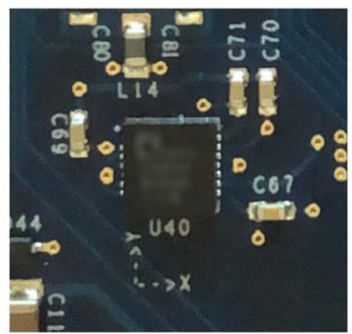

(b) Kionix KXRB5-2050

monitoring network through Wireless Meter Bus (Wireless M-Bus) protocol at $169 \mathrm{MHz}$ or $868 \mathrm{MHz}$ that allows communication over long distances and is much less exposed to obstacle attenuation. Also a Narrow Band Internet of things (NB-IoT) or 5G expansion module is available. This flexibility in terms of communication interfaces is the main advantage coming from this dedicated board design.

Finally, SHM-Board $v 2$ provides the capability to acquire signals from other types of measuring instruments like clino-meters and crack-meters, widely used in the field of Structural Health Monitoring (especially after seismic events that caused serious damages to the buildings). The integrated temperature sensor allows to evaluate the thermal effect on the structure and on the sensor thus allowing to distinguish seasonal variations from real inclinations. The MEMS operating principle guarantees good thermal stability and excellent linearity.

\subsection{Architecture supporting the SHM and EEW application}

The deployed application has been studied and tested with the limitations of the dedicated communications systems, D'Errico et al. (2019). However, the possibility to leverage an 
uRLLC infrastructure unveils tremendous potential benefits on safety of human beings and infrastructures.

As described in Fig. 4 the deployed service refers to a network of monitored building equipped with the developed sensor boards able to collect accelerometric data used to feed a data driven SHM system and an EEW detection service.

The University of L'Aquila, in collaboration with the municipality, has deployed an experimental network and a MEC elaboration server for the proposed service referring to, at the moment, 5 buildings ( 3 historical buildings, a RC building, and a base-isolated modern building). Figure 5 shows the location of the buildings in L'Aquila for the pilot experimentation with the Coppito 1 building, described in Sect. 5, located in "Polo Universitario di Coppito" site.

Referring to the first one and considering the scenario described in Fig. 2 the deployed architecture supports the communication within a remote cloud server able to estimate dynamical models for large-scale complex real-life systems via machine learning methodologies, Smarra et al. (2020), De Iuliis et al. (2021), De Iuliis et al. (2021), or continuously update a data-driven model of the monitored building.

Considering the EEW scenario, the idea is to send an early warning message as soon as the P-wave of the earthquake is detected, in order to inform the surrounding areas before the arrival of the possible destructive S-wave. This allows to notify people and surrounding structures for acting in order to preserve severe damages e.g. evacuate dangerous areas, initiate elevator recall procedures to ground floor, halt assembly lines, switch on emergency lights, slow trains and many other possibilities strictly related to the "smartness" of the territory involved.

Trivially, the lower is the time required for the propagation of the warning the higher is the effectiveness of such a system. This is the reason why, for the previously described

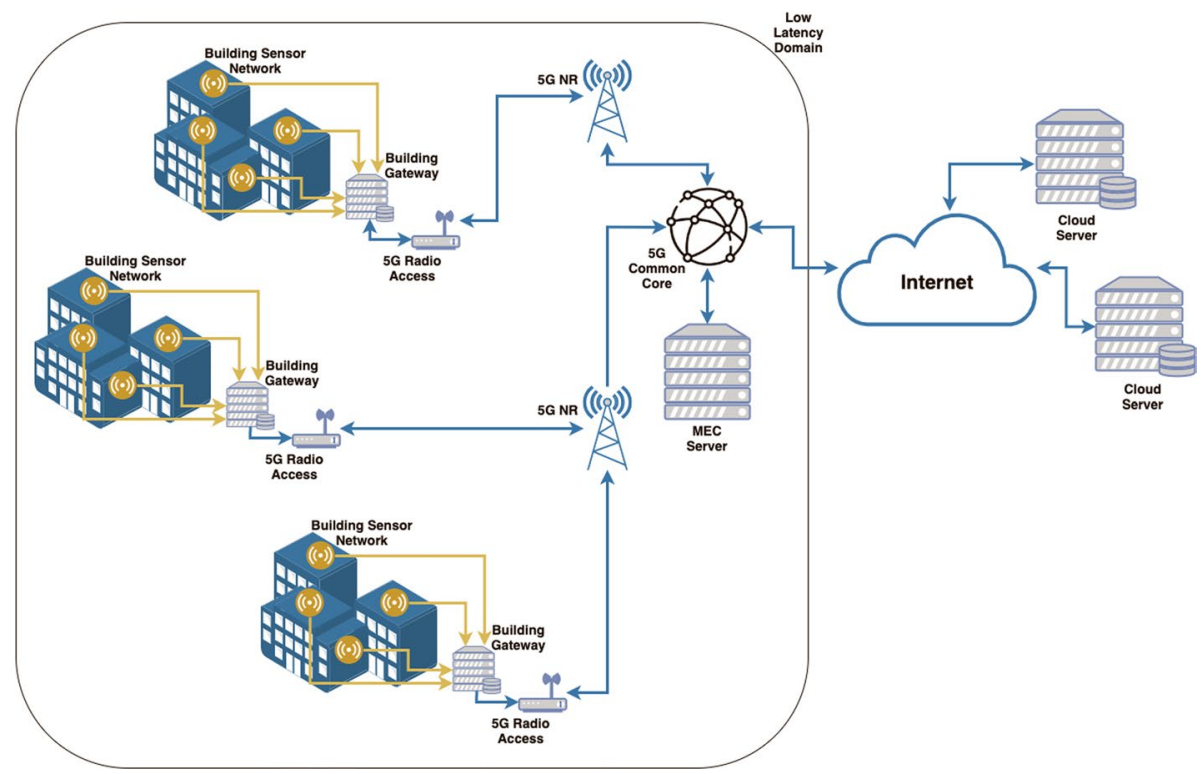

Fig. 4 Deployed IT architecture supporting the structural health monitoring and earthquake early warning application 


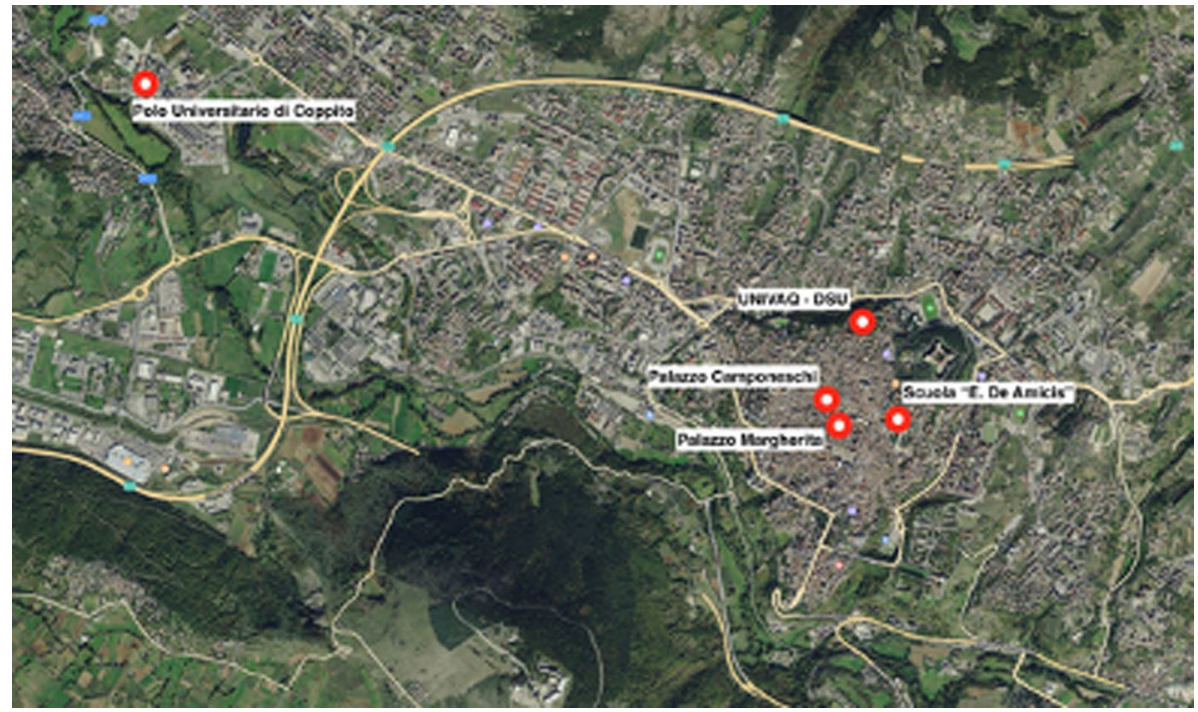

Fig. 5 Location of the buildings in L'Aquila for the pilot experimentation

scenario, an application running on a MEC server may receive and process data with a lower latency in order to quickly detect the propagation of a seismic wave.

In both scenarios, the exchange of data is implemented at the application layer through the Message Queue Telemetry Transport (MQTT) protocol based on the use of a broker, designed for the transmission of data according to the publish/subscribe pattern. According to this pattern each building acts as a publisher when sending early warning messages or a monitoring information to the broker. The broker, in turn, sends the collected data to all the interested buildings, them being subscribers at the same time.

\section{Case study}

The case study is focused on one of the most important buildings belonging to the University of L'Aquila, Ceci et al. (2010). The referenced building for the discussed case study, named "Renato Ricamo" (Coppito 1), was built in the 1985. A digital platform, some images of which are shown in Fig. 6, owned by the University of L'Aquila stores a series of information related to the referred building aiming to build a distribuited Digital Twin handling also data coming from the monitoring sensors. Figure 7 also shows some aerial view of the study case complex.

It is composed by six RC (Reinforced Concrete) substructures (C1-C6 in Fig. 8a) separated by seismic joints. Moreover, the first four buildings (C1-C4) are characterized by geometrical regularities, in both plan and elevation, while, on the contrary, the two central structures (C5 and C6) show a higher irregularity. Indeed, even if not well visible in Fig. 8a, they have staggered floors two of which with a central hole. The buildings C1-C4 are developed in elevation through four levels where the vertical structural part is composed by columns and RC walls. The horizontal ones are realized by beams and RC slabs alternated with predalles. Figure 8 also shows the positions of the sensors selected for each 


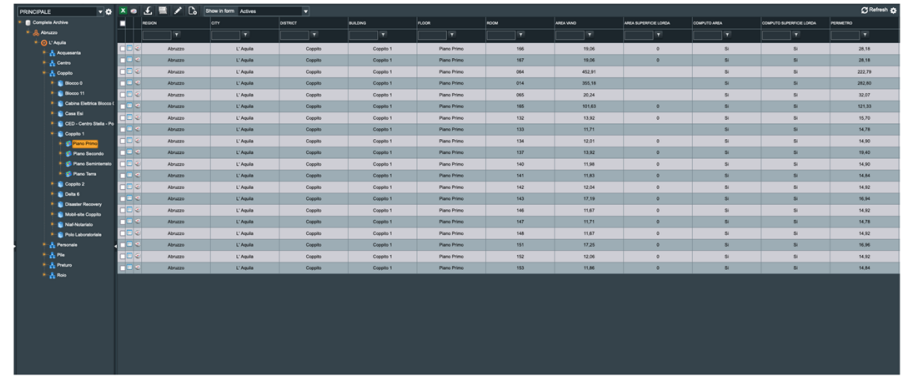

(a) Asset browser

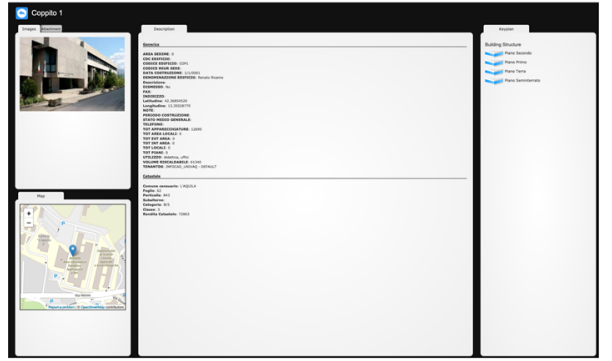

(b) Coppito 1 buildling summary

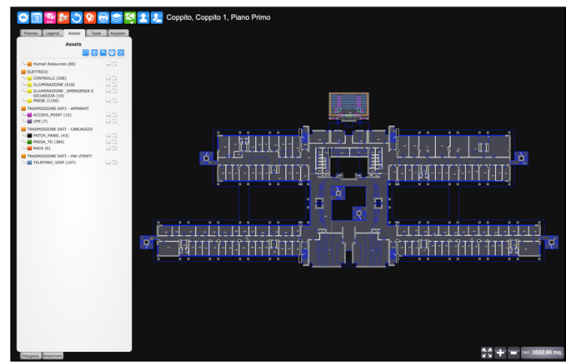

(c) Coppito 1 plan

Fig. 6 University platform for digital management of the buildings
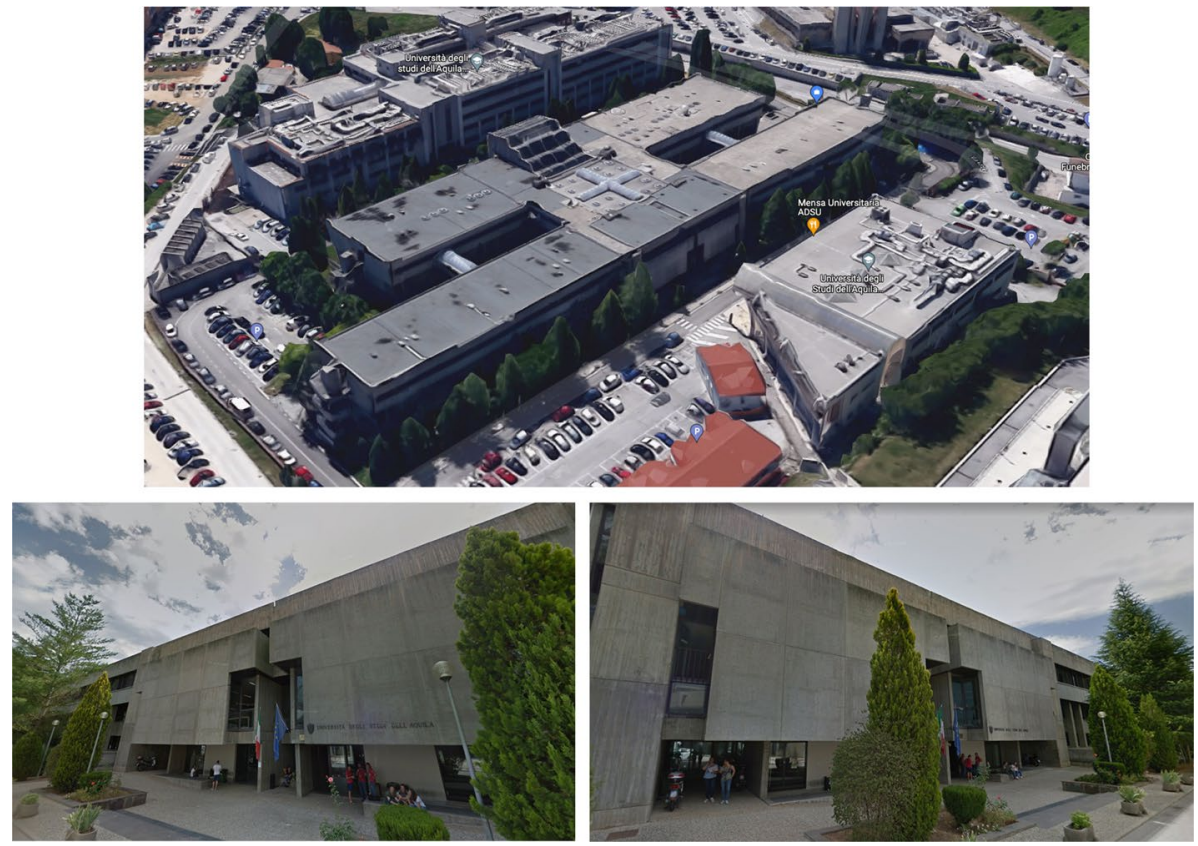

Fig. 7 Aerial view (above) and two lateral view photos (below) of the "Renato Ricamo" buildings 


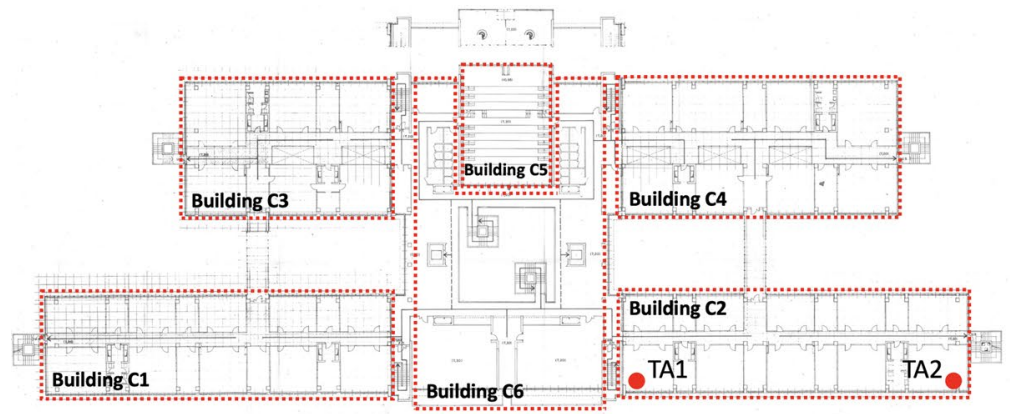

(a) General configuration of the "Renato Ricamo" buildings. TA1 and TA2: position of the tri-axial MEMS accelerometric sensors installed for the building C2 in the last and second-last floor.

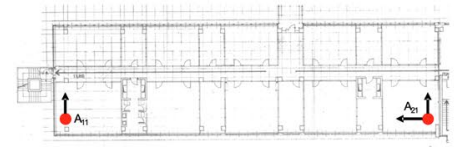

(b) Building $C 1$

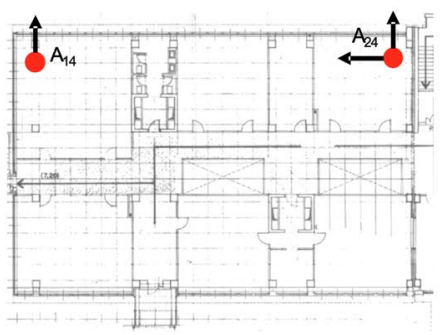

(d) Building $\mathrm{C}_{3}$

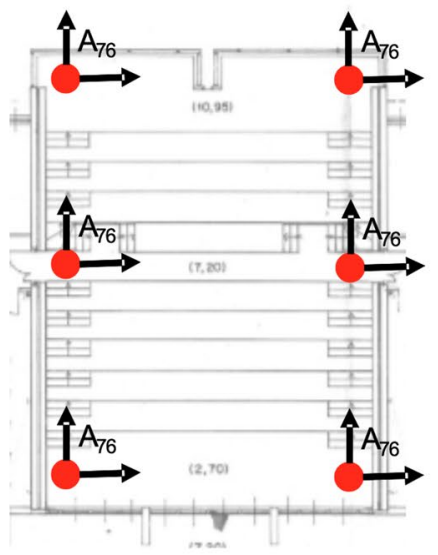

(f) Building $C 5$

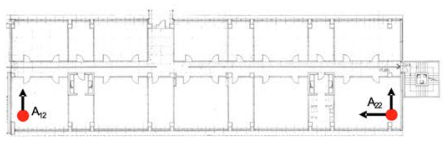

(c) Building C2

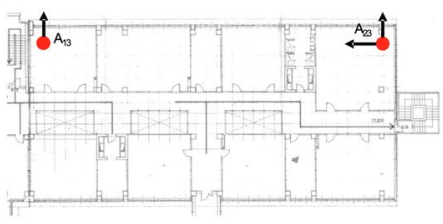

(e) Building $C_{4}$

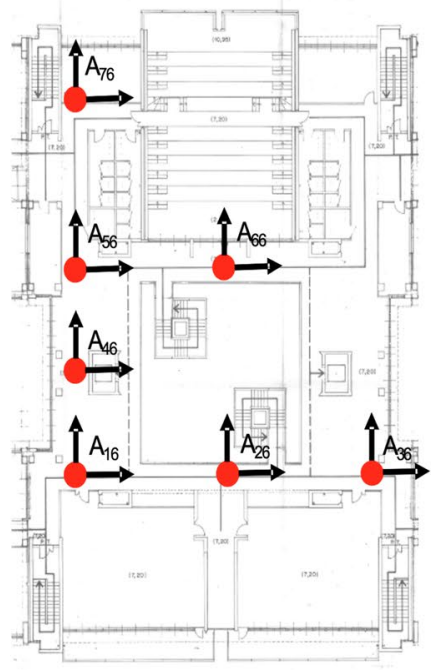

(g) Building C6

Fig. 8 Positions of the sensors selected for each building and elevation 
Table 1 Number of sensors for each building in Coppito 1

\begin{tabular}{llll}
\hline Building & Sensors/floor & Elevations & Total sensors \\
\hline C1 & 2 tri-axial & 4 & 8 \\
C2 & 2 tri-axial & 4 & 8 \\
C3 & 2 tri-axial & 4 & 8 \\
C4 & 2 tri-axial & 4 & 8 \\
C5 & 6 tri-axial & 1 & 6 \\
C6 & 7 tri-axial & 2 & 14 \\
\hline
\end{tabular}

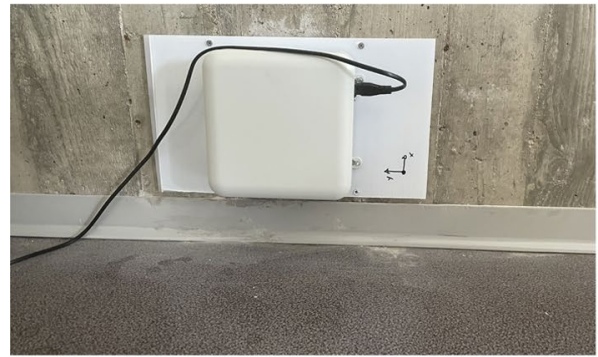

(a) Sensor TA1

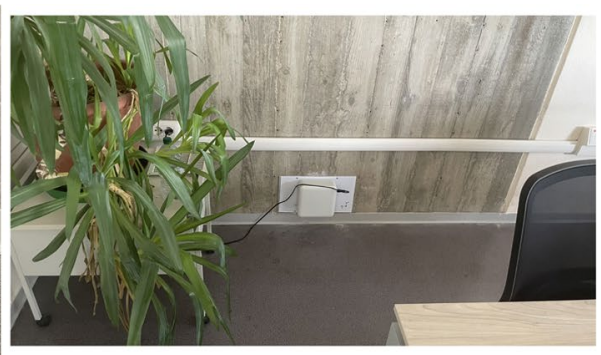

(b) Sensor TA2

Fig. 9 Deployed sensors for the fourth elevation of C2 building

building and elevation. Finally, Table 1 summarize number of sensors for each building in Coppito 1.

Currently, only four tri-axial MEMS accelerometric sensors have been installed: two in the last and two in the second-last floor of the building $\mathrm{C} 2$. They are located on the edges of the building (positions TA1 and TA2 in Fig. 8a) in order to identify the tridimensional dynamic behavior of the structure. Figure 9 reports the deployed sensors for the fourth elevation of $\mathrm{C} 2$ building.

MEMS are, in general, economic sensors but highly noisy. For this reason, performing a continuous structural health monitoring using measurements recorded under ambient vibrations is very difficult (for instance with the purpose of following the variation of the modal frequencies due to temperature or humidity). Indeed, the actual configuration, is thought to evaluate the real structural behavior processing recordings obtained under a seismic input. Even though not purely correct, the accelerations induced by low energy earthquakes could be used to approximately identify the main modal features, Potenza et al. (2015). In the following, the building C2 will be taken into account as test bed.

\subsection{Numerical model}

The finite element model of the test bed has been implemented within the environment Midas Gen (v2.2), [44]. Figure 10a highlights the different geometrical properties of the elements varying the colors ( 8 and 3 different sections for beams and plates, respectively, and listed in the Table 2).

Instead, Fig. 10b shows the type of the boundary conditions applied to all nodes on the base that block all six degrees of freedom. The model is composed by 150 nodes and 389 

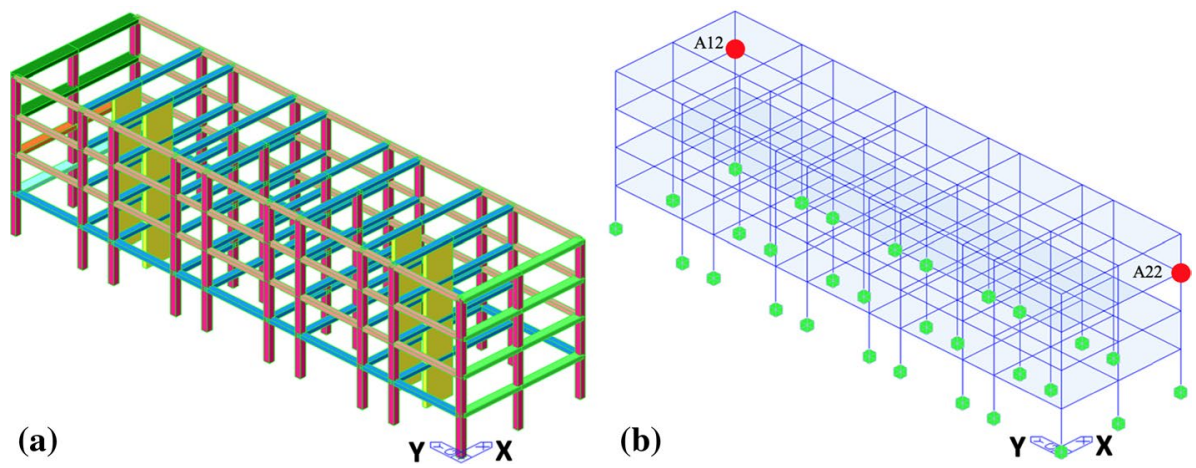

Fig. 10 Finite element model representative of the structural behavior of Coppito 1: a different elements typologies, b boundary conditions (fixed to the base)

Table 2 Sections and thickness used in the Finite Element Modelling

\begin{tabular}{|c|c|c|c|c|}
\hline Element & $\begin{array}{l}\text { Section } \\
\mathrm{H}(\mathrm{cm})\end{array}$ & $\begin{array}{l}\text { Section } \\
\mathrm{W}(\mathrm{cm})\end{array}$ & $\begin{array}{l}\text { Thickness } \\
(\mathrm{cm})\end{array}$ & Representativeness \\
\hline Beam & 60 & 60 & - & $\begin{array}{l}\text { All columns } \\
\text { (constant section for whole height) }\end{array}$ \\
\hline Beam & 300 & 40 & - & $\begin{array}{l}\text { R.C. walls of the stairwells } \\
\text { (yellow) }\end{array}$ \\
\hline Beam & 40 & 80 & - & $\begin{array}{l}\text { Transversal elements } \\
\text { (light green, X-direction) }\end{array}$ \\
\hline Beam & 35 & 105 & - & $\begin{array}{l}\text { Transversal elements } \\
\text { (cyan, X-direction) }\end{array}$ \\
\hline Beam & 40 & 60 & - & $\begin{array}{l}\text { Transversal elements } \\
\text { (blue, X-direction) }\end{array}$ \\
\hline Beam & 40 & 85 & - & $\begin{array}{l}\text { Transversal elements } \\
\text { (orange, X-direction) }\end{array}$ \\
\hline Beam & 40 & 120 & - & $\begin{array}{l}\text { Transversal elements } \\
\text { (dark green, X-direction) }\end{array}$ \\
\hline Beam & 40 & 45 & - & $\begin{array}{l}\text { Transversal elements } \\
\text { (light brown, Y-direction) }\end{array}$ \\
\hline Plate & - & - & 50 & $\begin{array}{l}\text { Horizontal elements } \\
\text { (floors) }\end{array}$ \\
\hline Plate & - & - & 7 & $\begin{array}{l}\text { Vertical elements } \\
\text { (external R.C. walls) }\end{array}$ \\
\hline
\end{tabular}

elements (273 beam and 116 plate). The model shows regularities in both plane and elevation (see Fig. 8a, building $C 2$ ) as shown by lateral view photos in Fig. 7. The reinforced concrete infills are present only between second and third floor (i.e. second elevation) and between third and fourth floor (i.e. forth elevation).

It is important to observe that the thickness used for the elements representing the floor (horizontal plates) was of $50 \mathrm{~cm}$ in order to take into account also the weight of the 

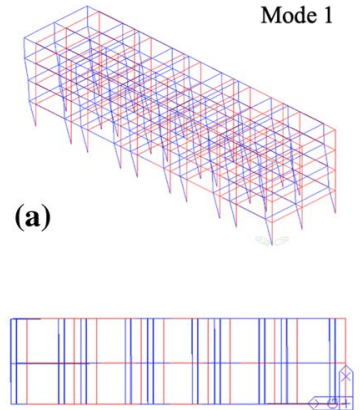

(b)
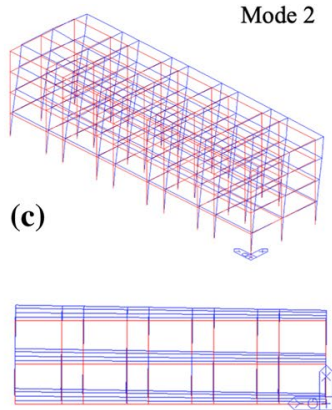

(d)
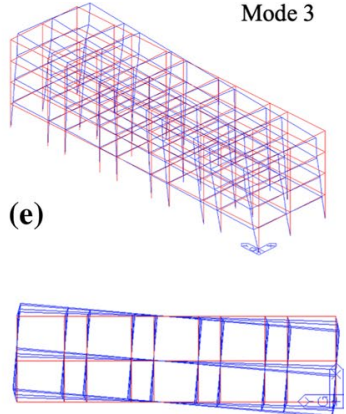

(f)

Fig. 11 Numerical modal shapes for the updated model: a, b translational in Y-direction (longitudinal); c, d translational in X-direction (transversal); e, f rotational

non-structural elements (screed, flooring, partitions, machineries, etc...). These latter are not considered in the definition of the elastic modulus for the floor (structural part with a thickness of $20 \mathrm{~cm}$ ) and this is the reason since a reduced value (about an half of the nominal value) has been used. In some sense, such selected value has been applied to taken into account an equivalence of the floor axial stiffness between model and actual structural configuration. Moreover, such elements contribute also to model the floors as infinitely rigid. The masses coming from the floors are automatically inserted in the nodes of the corresponding plate elements proportionally to the influence areas of each nodes.

An elastic-linear constitutive law has been defined for all elements whose parameters have been manually updated based on the information coming from the dynamic tests carried out by the University of L'Aquila Technical Office, [45]. In this last report, it can be found the main modal characteristics (frequencies, modal shapes and dampings) related to all substructures constituting the building of Coppito 1. In particular, the ones of the structure $C 2$ are reported in Table 3. Such parameters have been identified using the software ARTeMIS, Structural Vibration Solutions (2018), through the well-known procedures within implemented: EFDD, Brincker et al. (2001) and Stochastic Subspace Identification - Unweighted Principal Component (SSI-UPC, Peeters and De Roeck (1999)). It was considered reasonable to change only the elastic modulus in order to maintain close, as much as possible, the numerical and experimental modes. The minimization of the difference between the numerical and experimental modal frequencies of the modes mainly involved in the dynamic response has been chosen as objective function for updating the model.

Table 3 Main modal frequencies and shapes experimentally identified for the building $\mathrm{C} 2$ (results found in [45])

\begin{tabular}{lllll}
\hline Mode & $\begin{array}{l}\text { EFDD } \\
{[\mathrm{Hz}]}\end{array}$ & $\begin{array}{l}\text { SSI-UPC } \\
{[\mathrm{Hz}]}\end{array}$ & $\begin{array}{l}\text { Avg. freq. } \\
{[\mathrm{Hz}]}\end{array}$ & $\begin{array}{l}\text { Experimental } \\
\text { modal shape }\end{array}$ \\
\hline 1 & 2.695 & 2.704 & 2.700 & $\begin{array}{l}\text { translational } \\
\text { (longitudinal Y-direction) }\end{array}$ \\
2 & 2.968 & 2.985 & 2.977 & $\begin{array}{l}\text { roto-translational } \\
\text { (translational in X-direction) } \\
3\end{array}$ \\
3.802 & 3.774 & 3.788 & $\begin{array}{l}\text { roto-translational } \\
\text { (rotational) }\end{array}$ \\
\hline
\end{tabular}


Table 4 Characteristics of the elastic-linear constitutive laws for the updated model

\begin{tabular}{lllll}
\hline Element & $\begin{array}{l}\text { Elastic modulus } \\
\text { (initial) }(\mathrm{MPa})\end{array}$ & $\begin{array}{l}\text { Elastic modulus } \\
\text { (final) }(\mathrm{MPa})\end{array}$ & $\begin{array}{l}\text { Poisson } \\
\text { Coefficient }\end{array}$ & $\begin{array}{l}\text { Specific weight } \\
\left(\mathrm{Kg} / \mathrm{m}^{3}\right)\end{array}$ \\
\hline Beam & 32000 & 31475 & 0.2 & 2500 \\
Columns & 32000 & 31475 & 0.2 & 2500 \\
Walls & 32000 & 31475 & 0.2 & 2500 \\
Floor & 16000 & 19475 & 0.2 & 2600 \\
\hline
\end{tabular}

Table 5 Comparison between numerical and experimental frequencies (Coppito 1, building C2)

\begin{tabular}{llll}
\hline Mode & Numerical $(\mathrm{Hz})$ & Experimental $(\mathrm{Hz})$ & $\Delta(\%)$ \\
\hline 1 & 2.648 & 2.700 & -1.91 \\
2 & 2.966 & 2.977 & 0.35 \\
3 & 3.993 & 3.788 & 5.41 \\
\hline
\end{tabular}

The corresponding expression related to the first three modes (total participating masses of such three modes: translational X-direction $=81.83 \%$, translational Y-direction $=95.51 \%$, translational Z-direction $=0.09 \%$, rotational X-direction $=0.10 \%$, rotational Y-direction $=$ $0.10 \%$, rotational Z-direction $=86.90 \%$ ) is shown by equation $(1)$.

$$
F(E)=\min \sum_{i=1}^{3} \frac{f_{i}^{\text {exp }}-f_{i}^{\text {num }}}{f_{i}^{\text {num }}}
$$

where $F$ is the objective function depending by the elastic modulus, $E$, while $f_{i}^{\text {exp }}$ and $f_{i}^{n u m}$ are the $\mathrm{i}-t$ th experimental and numerical frequencies, respectively. The final parameters are reported in Table 4, where have been reported both initial and updated elastic modulus, while in Fig. 11 the modal shapes related to the updated model are shown.

Table 5 reports a comparison between the numerical and experimental modal frequencies. The first two modes (translational in the X- and Y-direction) are in good agreement showing a percentage difference of -1.91 and $0.35 \%$, respectively. Related to the third one (rotational), a difference slightly higher than the $5 \%$ has been found $(5.41 \%)$ that, in any way, has been retained acceptable. It is worth to highlight that the last choices of the elastic modulus (the only parameters varying), provide also a good agreement between numerical and identified modal shapes: for the last ones refer to the report provided by the University of L'Aquila, University of L'Aquila (2017). The comparison has been carried out only visually.

\subsection{Simulation results}

Successively, such numerical model has been used to generate the time histories of a damaged and non-damaged configuration under white noise. The latter has been realized in Simulink through the block "Band-Limited White Noise". The damage has been simply modelled by a reduction of the elastic modulus. This simplification has been assumed in order to make the results more easily manageable and understandable and, above all, to 

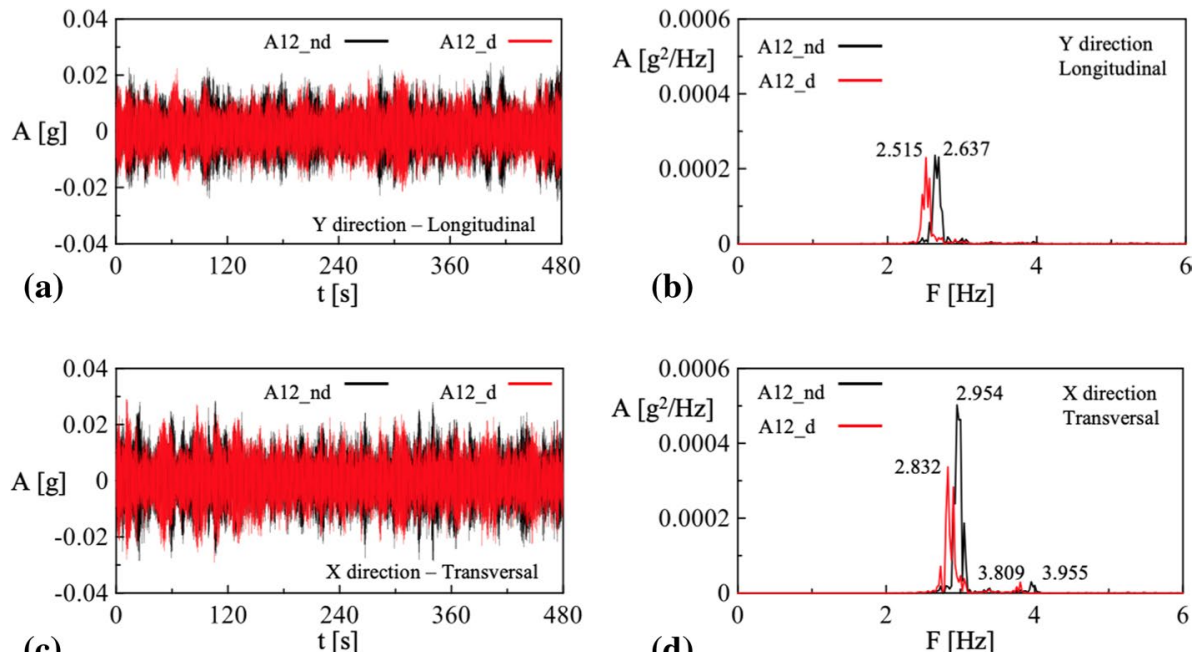

(c)

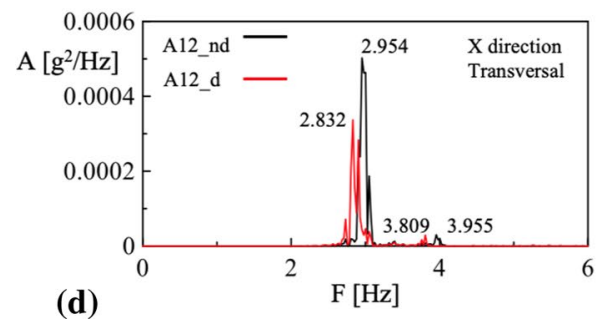

Fig. 12 Numerical simulations under white noise related to the nodes A12: a, c time histories, b, d PSDs; nd = non-damaged, $\mathrm{d}=$ damaged

allow a check of the IT system performance. The time histories have been extracted from the nodes positioned in A11 and A12 (see Fig. 10b) and have been reported in Fig. 12a, c and Fig. 13a, c. The effect of the damage is clearly visible when observing the corresponding Power Spectral Densities (PSDs reported in in Fig. 12b, d and Fig. 13b, d). Indeed, the damage affects the modal frequencies producing a reduction especially recognizable on the translation modes. Instead, the rotational mode is poorly identifiable in both damaged and non-damaged configuration.
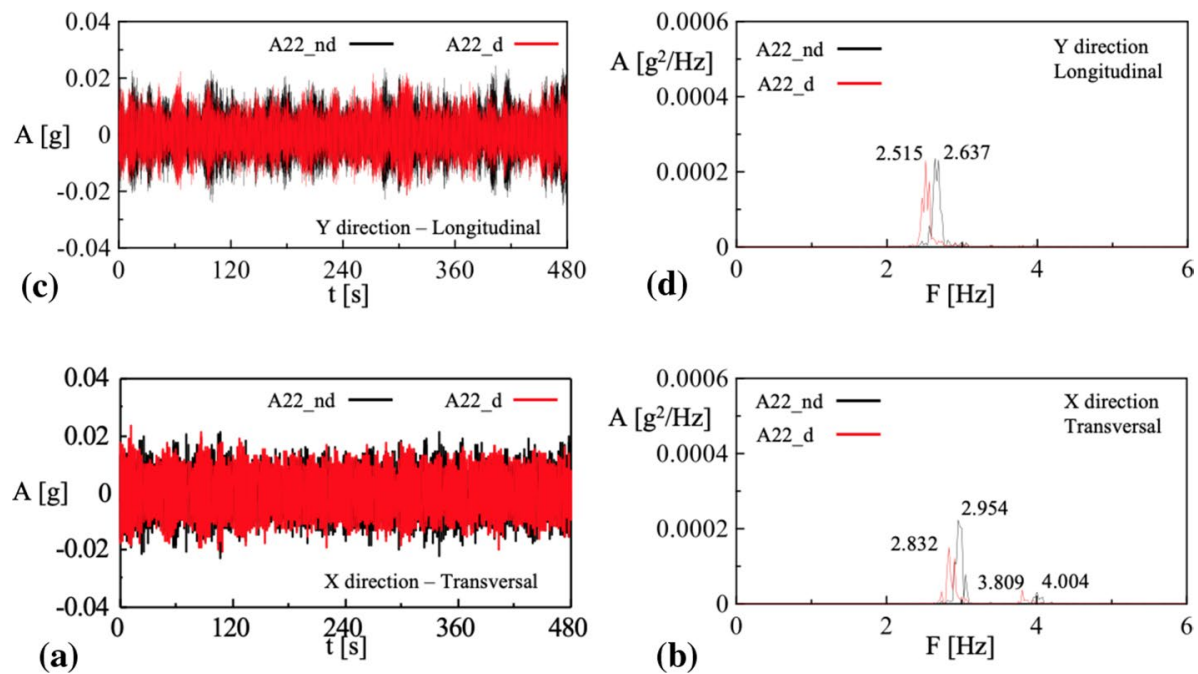

Fig. 13 Numerical simulations under white noise related to the node A22: a, c time histories, b, d PSDs; nd $=$ non-damaged, $\mathrm{d}=$ damaged 
About the damaged configuration, an approximate reduction of the $10 \%$ has been applied to the value of the elastic modulus. Of course, during the processing of real data, coming from a continuous monitoring system, to accurately detect the presence of damage, the main modal characteristics (frequencies and modal shapes) should be identified, purifying the results by the effect of the environmental parameters (e.g., humidity and temperature).

\subsection{Time series feeding a prototype MATLAB processing application}

A prototype application, developed in MATLAB, able to connect through an User Datagram Protocol (UDP) socket with the building gateway, has been used to implement a Machine Learning (ML) based approach for SHM for continuous refining of the model. The time series previously described and representing the building in its elastic condition have been used to evaluate the capability of the deployed application to update the datadriven model obtained from the continuous monitoring of the structure. The same application deployed on MEC nodes of the IT architecture of Sect. 4.2 is able to process the same data near-real time (low latency) and, when they are referred to a damaged structure, to send an alarm to the damaged building.

Some measurements were made on the developed scenarios. The average delay of the network, at application layer, follows a normal distribution with an average value of $2.1 \mathrm{~ms}$ and a standard deviation of $0.9 \mathrm{~ms}$. Sensors data were sent to the edge and remote cloud and delays were assessed. Publish messages were generated every $10 \mathrm{~ms}$ by the publisher, with MQTT QoS set to zero.

\section{Conclusions}

This contribution has presented a system for Structural Health Monitoring on 5G uRLLC network where data-driven algorithms are applied for data exploitation as well as for early warning systems implementation. Such algorithms can be also used to periodically improve the models as data are collected from sensors by catching new dynamics as structure evolves over time (changes or degradation of certain points of the structure). A real scenario based on a RC structure has been studied. The developed finite element model has been used to generate data referred to health and damaged conditions of the monitored building in order to verify the behaviour of the service. Future works are devoted toward the exploitation of real-time experimental data for service validation. Operational Modal Analysis allowing frequencies identification in the presence of ambient vibrations is currently under evaluation.

Acknowledgements The research leading to these results has received funding from the Italian Government under CIPE resolution n.135 (Dec. 21. 2012) under the project INCIPICT - INnovating City Planning through Information and Communication Technologies and from the research project DESDEMONA - DEtection of Steel Defects by Enhanced MONitoring and Automated procedure for self-inspection and maintenance (grant agreement number RFCS-2018_800687) supported by EU Call RFCS-2017.

Open Access This article is licensed under a Creative Commons Attribution 4.0 International License, which permits use, sharing, adaptation, distribution and reproduction in any medium or format, as long as you give appropriate credit to the original author(s) and the source, provide a link to the Creative Commons licence, and indicate if changes were made. The images or other third party material in this article are included in the article's Creative Commons licence, unless indicated otherwise in a credit line to the 
material. If material is not included in the article's Creative Commons licence and your intended use is not permitted by statutory regulation or exceeds the permitted use, you will need to obtain permission directly from the copyright holder. To view a copy of this licence, visit http://creativecommons.org/licenses/by/4.0/.

\section{References}

Anastasopoulos D, De Roeck G, Reynders EP (2021) One-year operational modal analysis of a steel bridge from high-resolution macrostrain monitoring: influence of temperature vs. retrofitting. Mech Syst Signal Process 161:107951

Antonelli C, Cassioli D, Franchi F, Graziosi F, Marotta A, Pratesi M, Rinaldi C, Santucci F (2018) The city of L'Aquila as a living lab: the INCIPICT project and the 5g trial. In: 2018 IEEE 5G World Forum (5GWF). IEEE, pp 410-415

Brincker R, Zhang L, Andersen P (2001) Modal identification of output-only systems using frequency domain decomposition. Smart Mater Struct 10(3):441

Ceci AM, Gattulli V, Potenza F (2013) Serviceability and damage scenario in irregular rc structures: postearthquake observations and modeling predictions. J Perform Construct Facilities 27(1):98-115

Ceci A, Contento A, Fanale L, Galeota D, Gattulli V, Lepidi M, Potenza F (2010) Structural performance of the historic and modern buildings of the university of l'aquila during the seismic events of April 2009. Eng Struct 32(7):1899-1924

Chiarabba C, Amato A, Anselmi M, Baccheschi P, Bianchi I, Cattaneo M, Cecere G, Chiaraluce L, Ciaccio M, De Gori P et al (2009) The 2009 L'Aquila (central italy) mw6. 3 earthquake: main shock and aftershocks. Geophys Res Lett 36(18)

De Iuliis V, Smarra F, Manes C, D'Innocenzo A (2021) On the stability of switched arx models, with an application to learning via regression trees. IFAC-PapersOnLine 54(5):61-66

De Iuliis V, Di Girolamo G D, Smarra F, D'Innocenzo A (2021) A comparison of classical identification and learning-based techniques for cyber-physical systems. In: 2021 29th Mediterranean conference on control and automation (MED), pp 179-185, IEEE

D'Errico L et al. (2019) Structural health monitoring and earthquake early warning on $5 \mathrm{~g}$ urllc network. In: 2019 IEEE 5th world forum on internet of things (WF-IoT), IEEE

Di Girolamo G D, Smarra F, Gattulli V, Potenza F, Graziosi F, D‘Innocenzo A (2020) Data-driven optimal predictive control of seismic induced vibrations in frame structures. Struct Control Health Monit 27(4):e2514

Di Stefano R, Chiarabba C, Chiaraluce L, Cocco M, De Gori P, Piccinini D, Valoroso L (2011) Fault zone properties affecting the rupture evolution of the 2009 ( $\mathrm{mw} 6.1$ ) l'aquila earthquake (central italy): insights from seismic tomography. Geophys Res Lett 38(10)

Diaferio M, Foti D, Potenza F (2018) Prediction of the fundamental frequencies and modal shapes of historic masonry towers by empirical equations based on experimental data. Eng Struct 156:433-442

Diaferio M, Foti D, Gentile C, Giannoccaro NI, Saisi A (2015a) Dynamic testing of a historical slender building using accelerometers and radar. In: 6th International operational modal analysis conference (IOMAC 2015), Ediciones Univ Oviedo, Serv Publicaciones Univ Oviedo, Campus Humanidades, pp $1-10$

Diaferio M, Foti D, Giannoccaro NI (2015b) Identification of the modal properties of a building of the greek heritage. Key Eng Mater 628:150-159

Dolce M, Nicoletti M, De Sortis A, Marchesini S, Spina D, Talanas F (2017) Osservatorio sismico delle strutture: the Italian structural seismic monitoring network. Bull Earthquake Eng 15(2):621-641

Flah M, Nunez I, Chaabene WB, Nehdi ML (2021) Machine learning algorithms in civil structural health monitoring: a systematic review. Arch Comput Methods Eng 28(4):2621-2643

Foti D (2015) Non-destructive techniques and monitoring for the evolutive damage detection of an ancient masonry structure. Key Eng Mater, Trans Tech Publ 628: 168-177

Foti D, Giannoccaro NI, Vacca V, Lerna M (2020) Structural operativity evaluation of strategic buildings through finite element (fe) models validated by operational modal analysis (oma). Sensors 20(11):3252

Gattulli V, Cunha A, Caetano E, Potenza F, Arena A, Di Sabatino U (2021) Dynamical models of a suspension bridge driven by vibration data. Smart Struct Syst 27(2):139

Gentile C, Guidobaldi M, Saisi A (2016) One-year dynamic monitoring of a historic tower: damage detection under changing environment. Meccanica 51(11):2873-2889

Gentile C, Ruccolo A, Canali F (2019) Long-term monitoring for the condition-based structural maintenance of the milan cathedral. Construct Build Mater 228:117101 
Giordano PF, Quqa S, Limongelli MP (2021) Statistical approach for vibration-based damage localization in civil infrastructures using smart sensor networks. Infrastructures 6(2):22

Güemes A, Fernandez-Lopez A, Pozo AR, Sierra-Pérez J (2020) Structural health monitoring for advanced composite structures: A review. J Comp Sci 4(1):13

Jacobsen N-J, Andersen P, Brincker R (2008) Applications of frequency domain curve-fitting in the efdd technique. In: Conference proceedings: IMAC-XXVI: a conference and exposition on structural dynamics. Soc Exp Mech

Kaya Y, Safak E (2015) Real-time analysis and interpretation of continuous data from structural health monitoring (shm) systems. Bull Earthquake Eng 13(3):917-934

Kita A, Cavalagli N, Ubertini F (2019) Temperature effects on static and dynamic behavior of consoli palace in Gubbio, Italy. Mech Syst Signal Process 120:180-202

Kita A, Cavalagli N, Masciotta MG, Lourenço PB, Ubertini F (2020) Rapid post-earthquake damage localization and quantification in masonry structures through multidimensional non-linear seismic ida. Eng Struct 219:110841

Krishnamurthy V, Fowler K, Sazonov E (2008) The effect of time synchronization of wireless sensors on the modal analysis of structures. Smart Mater Struct 17(5):055018

Limongelli M P, Giordano P F (2020) Vibration-based damage indicators: a comparison based on information entropy. J Civil Struct Health Monit, pp 1-16

Lynch JP, Loh KJ (2006) A summary review of wireless sensors and sensor networks for structural health monitoring. Shock Vib Digest 38(2):91-130

MIDAS, MIDAS/GEN (Integrated Design System for Buildings and General Structures)

Mustapha S, Lu Y, Ng C-T, Malinowski P (2021) Sensor networks for structures health monitoring: placement, implementations, and challenges-a review. Vibration 4(3):551-585

Ostachowicz W, Soman R, Malinowski P (2019) Optimization of sensor placement for structural health monitoring: a review. Struct Health Monit 18:963-988

Peeters B, De Roeck G (1999) Reference-based stochastic subspace identification for output-only modal analysis. Mech Syst Signal Process 13(6):855-878

Peng T, Nogal M, Casas JR, Turmo J (2021) Planning low-error shm strategy by constrained observability method. Auto Construct 127:103707

Pitilakis K, Karapetrou S, Bindi D, Manakou M, Petrovic B, Roumelioti Z, Boxberger T, Parolai S (2016) Structural monitoring and earthquake early warning systems for the ahepa hospital in thessaloniki. Bull Earth Eng 14(9):2543-2563

Potenza F, Rinaldi C, Ottaviano E, Gattulli V (2020) A robotics and computer-aided procedure for defect evaluation in bridge inspection. J Civil Struct Health Monit 10(3):471-484

Potenza F, Federici F, Lepidi M, Gattulli V, Graziosi F, Colarieti A (2015) Long-term structural monitoring of the damaged "Basilica S. Maria di Collemaggio" through a low-cost wireless sensor network. J Civil Struct Health Monit, 5(5):655-676

Rainieri C, Notarangelo MA, Fabbrocino G (2020) Experiences of dynamic identification and monitoring of bridges in serviceability conditions and after hazardous events. Infrastructures 5(10):86

Reynders E, De Roeck G (2008) Reference-based combined deterministic-stochastic subspace identification for experimental and operational modal analysis. Mech Syst Signal Process 22(3):617-637

Shafi M, Molisch AF, Smith PJ, Haustein T, Zhu P, De Silva P, Tufvesson F, Benjebbour A, Wunder G (2017) 5g: A tutorial overview of standards, trials, challenges, deployment, and practice. IEEE J Selected Areas Commun 35(6):1201-1221

Smarra F, Di Girolamo GD, De Iuliis V, Jain A, Mangharam R, D’Innocenzo A (2020) Data-driven switching modeling for mpc using regression trees and random forests. Nonlinear Anal Hybrid Syst 36:100882

Smarra F, Di Girolamo GD, Gattulli V, Graziosi F, D’Innocenzo A (2020) Learning models for seismicinduced vibrations optimal control in structures via random forests. J Opt Theory Appl 1-20

Structural Vibration Solutions (2018) ARTeMIS Modal. Version 4:1998-2014

Ubertini F, Cavalagli N, Kita A, Comanducci G (2018) Assessment of a monumental masonry bell-tower after 2016 central italy seismic sequence by long-term shm. BulL Earthquake Eng 16(2):775-801

University of L'Aquila (2017) Technical Office RPID C1: Relazione prove identificazione dinamica Coppito 1 [in Italian]

Venanzi I, Kita A, Cavalagli N, Ierimonti L, Ubertini F (2020) Earthquake-induced damage localization in an historic masonry tower through long-term dynamic monitoring and fe model calibration. Bull Earthquake Eng 18(5):2247-2274

Publisher's Note Springer Nature remains neutral with regard to jurisdictional claims in published maps and institutional affiliations. 


\section{Authors and Affiliations}

\section{Vincenzo Gattulli ${ }^{1}$ D Fabio Franchi ${ }^{2} \cdot$ Fabio Graziosi $^{2} \cdot$ Andrea Marotta $^{2}$. Claudia Rinaldi ${ }^{2}$. Francesco Potenza ${ }^{3}$. Umberto Di Sabatino ${ }^{4}$}

Fabio Franchi

fabio.franchi@univaq.it

Fabio Graziosi

fabio.graziosi@univaq.it

Andrea Marotta

andrea.marotta@univaq.it

Claudia Rinaldi

claudia.rinaldi@univaq.it

Francesco Potenza

francesco.potenza@unich.it

Umberto Di Sabatino

umberto.disabatino@univaq.it

1 Department of Structural and Geotechnical Engineering, Sapienza University of Rome, Via Eudossiana 18, 00184 Rome, Italy

2 Department of Information Engineering, Computer Science and Mathematics, Università degli Studi dell'Aquila, Via Vetoio, 67100 L'Aquila, Italy

3 Department of Engineering and Geology, University G. D'Annunzio of Chieti-Pescara, Viale Pindaro 42, 65127 Pescara, Italy

4 Department of Civil, Construction-Architectural and Environmental Engineering, Università degli Studi dell'Aquila, Piazzale E. Pontieri 2, 67100 L'Aquila, Italy 